\title{
When the Virtual Becomes Real?
}

\begin{abstract}
In the first part of this final chapter, we look at several current trends in technologies used to enable various forms of digital travel, and some recent innovations-including social telepresence robots, drones, holograms and immersive VR. We briefly describe the approach and evaluate the pros and cons and potential of each, then move on to speculations about future directions and new possibilities. We present a method of stimulating new design ideas for digital travel, based on metaphors and blending theory. We illustrate the method using the metaphor: "To use my device is to travel". In the second part of the chapter, we recap and finalise our journey through the book.
\end{abstract}

Keywords Social telepresence robots - Drones · Holograms - Immersive VR · Metaphor · Blends

\section{INTRODUCTION}

The restrictions on meetings and travel that have come with the COVID19 pandemic have led to enormous change in behaviour and attitudes about the practicality and acceptability of replacing physical encounters with virtual ones. Many different kinds of meetings take place without physical travel; for example, concerts, school and college classes, sports

(C) The Author(s) 2022

I. Tjostheim and J. A. Waterworth, The Psychosocial Reality

of Digital Travel, https://doi.org/10.1007/978-3-030-91272-7_6 
events, academic and other conferences, training and personal development courses. What do we mean by "take place"? As introduced in Chapter 1, Meyrowitz (1986) described how modern communication media commonly lack a sense of place for the communicants. He suggested that they do not really have face-to-face meetings, since the participants are in different physical places and do not share an experience of being in the same place. The meetings do not "take place". They also lack the elements of departure, passage and arrival that characterise travel (Leed, 1991). In this section, we outline the strengths and weaknesses of using digital technology to meet others without having the sensation of travel.

Having meetings without physically being in the same place as the other participants saves time and resources; it is also relatively good for the environment. However, it is no accident that "Zoom fatigue" has become a common term for the exhaustion many people feel after spending much time in digitally mediated meetings (whether on Zoom or some other technological platform). One reason might be that, since people travel less currently, they spend more time in meetings overall. But there are several other possible reasons that reflect the psychosocial reality of digital meetings.

Bailenson (2021) identified four main reasons for what he calls "nonverbal overload". Firstly, with the typical laptop or desktop computer configuration used for such meetings, people experience too much, very close, eye contact, often with people we don't know well. Secondly, seeing oneself during social interactions is unnatural, and results in selfconsciousness and self-dissatisfaction, which is also fatiguing. Thirdly, we move less, and bodily movements normally aid our cognition and sense of comfort. Finally, because of the absence of natural nonverbal cues, for example, related to eye-contact and head movements, video meetings are more cognitively demanding and therefore tiring. A recent study by Fauville et al. (2021) found that women generally suffer more Zoom fatigue than men, partly because they tend to have longer meetings and shorter breaks, and also because they are more sensitive to seeing their own video image in this social context.

Face-to-face digital meetings are not really face-to-face, because, as Meyrowitz (1986) pointed out, the participants are not physically together. Only the face is seen, the rest of the body is out of view, whereas in physical meetings our whole bodies participate to provide nonverbal cues that help people communicate. 
Another issue with digital interaction with distant others is lag-a delay introduced by the communication network. Even though the time lag between exchanges is generally less than was the case with old telephonic systems, it still affects interaction. It is well known (e.g. Short et al., 1976) that a perceptible delay in a person's responses can give the impression of hesitancy, perhaps even dishonestly (since we tend to delay when reflecting before responding, and this might be the time needed to come up with a less than honest answer). There is a measurable negative effect on social presence (Cui, et al., 2013). The typical lag on a modern teleconferencing system is around $0.6 \mathrm{~s}$, whereas to be imperceptible the lag needs to be less than 0.2s (Gunawardena, 1995). Lack of synchronisation between audio and video is also often a problem, with video "freezes" not being uncommon. Time and synchronisation issues add to the increase cognitive load of digital meetings, along with low fidelity or distorted sound and vision. This combination might also be expected to result in reduced memorability for digital communication, analogous to the effect found with synthetic speech (Waterworth \& Thomas, 1985) since the increased cognitive load of accurately perceiving content reduces that available for mental interpretation and storage.

We can see several clear developments in the way people travel and meet, using digital technology. There are obvious and widespread developments, such as the expanded use of teleconferencing systems described above, accessed by computer, tablet and phone. These have been very successful in allowing a wide range of social activities to continue despite restrictions on travel. But, as outlined earlier in the book, they do not fully satisfy the psychosocial needs of their users. They are tiring and stressful for many. They do not provide a positive travel experience, a sense of being there, in another place with other people, away from the physical location of the body. We need to have the sense that we are embodied in another place, even though we are not. A variety of responses to this need have emerged already, which we outline in the rest of this section.

\section{Recent Innovations in Digital Travel}

In this section, we briefly outline two recent strands in ways of innovating digital travel. The first is represented by social telepresence robots and drones, the second by immersive VR and the use of holographic representations. 


\section{Social Telepresence Robots and Drones}

The idea behind social telepresence robots is to combine functionalities common to teleconferencing systems with physical presence in a distant location via a robot. Their use in this way represents a set of approaches that stress the need for a proxy physical presence in the distant location, but downplay the need for a strong sense of psychological presence there. They have their roots in remote manipulation systems that provide both views of, and the capacity for surrogate action in, a remote location.

Tsui et al. (2011) describe social telepresence robots as "embodied video conferencing on wheels". The typical set up is for there to be a simple robot that can be controlled by a person in another location. The robot includes a video camera and a screen, on which the remote person's image (captured by the camera of their communication device) is displayed. Such an arrangement is typically used so that a person at home can "attend" a meeting in their place of employment, visit a public place such as a museum or conduct remote inspections at factories or hospitals. The remote person can move around the place (via the robot), observe people and things from different viewpoints, visit and speak to different people - for example, people in different offices or hospital beds-and be seen and heard by the people there, via the physical presence provided by the social telepresence robot.

Social telepresence robotics is an expanding field, although not many evaluative studies have been conducted as yet. In a few cases social robots have sometimes been given a human, or other animate-creature, form (Kristoffersson, 2013).

A recent qualitative study of the use of telepresence robots to relieve social isolation in older adults before and during the Covid-19 pandemic (Isabet et al., 2021) found that acceptance levels were good, although they drew no conclusions about whether the robots were more beneficial during the pandemic than before. They do, however, point to a number of issues that need to be investigated further, including usability and functionality for social interaction.

Social drones are in some ways a more flexible approach than the use of robots, since they can in principle go anywhere at any time-whereas there has be a robot positioned at a remote site for social interaction to be achieved. Shakeri and Neustaedter (2019) reported on a prototype system called Teledrone, which combines a drone and controlling interface with what is essentially a teleconferencing system. The envisaged use 
case was for distant participant to share in an outdoor activity, such as hiking, and drones clearly have the advantage of being able to cross and communicate over difficult terrain and bodies of water. According to the authors, "Teledrone provides an embodiment for a remote user and can help support spatial awareness" (from the abstract). In principle, this kind of approach can be used almost anywhere, even with the drone moving indoors or into confined spaces, although there may be safety issues when drones are used in this way.

\section{Immersive VR Approaches and the Use of Holograms}

At the time of writing, Oculus (the VR-technology company owned by Facebook) is using the slogan: "Defy reality and distance", which could stand as a general call to take up digital travel. Facebook CEO Mark Zuckerberg indicated in an article in The Verge (23 July, 2021) that he sees the future of Facebook as a "metaverse" company. According to the article, Zuckerberg said: "A lot of the meetings that we have today, you're looking at a grid of faces on a screen. That's not how we process things either". Describing how interacting in immersive virtual reality would change that situation, he is reported as saying: "You feel present with other people as if you were in other places, having different experiences that you couldn't necessarily do on a 2D app or webpage...".

Full-body immersion has some advantages, in that it is possible to convey a very rich sense of being in another place, but action in the remote place is problematic unless the place exists only virtually. It all has profound social disadvantages. Despite its power for conveying a sense of being in another place, there are inherent difficulties in using immersive VR from a variety of locations, especially public or social locations encountered physically in everyday life.

The more one is immersed in a virtual world, the more one is cut off from the physical world in which the body is located. Just wearing a head-mounted display can open up a distant place as if one were there-at least visually and auditorily. But it also renders the wearer vulnerable to any threats, dangers and social antagonism such as ridicule in the actual place the physical body is located. Where people are happy to escape from a dull situation into their phones-waiting for a bus or riding on an underground train-the same is unlikely to apply when wearing a headmounted display. The power and attraction of phones and other mobile devices is partly that people can devote some attention to both the current 
physical world and the virtual happenings displayed on the device. The way these two worlds are mixed is far from optimal, both for the user or the other people involved (both locally and at a distance), but people manage, for example, to chat with distant others while finding their way through a train station. This would clearly not be the case with immersive VR.

Nevertheless, immersive VR of one kind or another is likely to become increasingly popular as an effective way of experiencing a distant place and events presented there, from a fixed and secure physical location; in the privacy of a home office, for example. In a completely virtual world, with full-body tracking and immersive displays, all kinds of action are possible, including some not possible with the body in the physical world, such as flying or passing through walls. Body tracking and immersive displays can also be combined with technologies such as robots or drones, allowing digital travel to actual places, though this needs to be carefully regulated because of obvious safety concerns.

The use of holograms is predicted to be the next big innovation in teleconferencing. In this set up, two or more locations are linked, as in a conventional teleconference, but participants in different locations see each other as holographic representations with a life-size 3D representation displayed in a specially equipped booth, rather than on a small screen (see e.g. Wired, 2021). The technology has been available for a decade or more, but is expected to become both more affordable and in great demand, largely due to changes in needs and attitudes brought about by restrictions in physical travel. While holograms might well become a fairly popular way of improving the vividness and intimacy of digital meetings, they are restricted to special, generally small, and expensively equipped rooms (or large booths) at both ends. Clearly, this is not compatible with flexible digital travel, either in terms of where one can be while travelling, or where one can travel to.

In contrast to the use of social telepresence robots and drones, immersive VR and holographic approaches both stress a vivid sense of psychological presence, but do not afford action in another physical place. They currently share a dependency on a fixed geographical location when interacting with distant people and places. This might change with the rapid pace of technological development, but social acceptance and safety concerns limit such use. 


\section{Rethinking Digital Travel}

To conclude this section, we consider below the ways in which the physical and the virtual can be blended to support embodied interaction in integrated places that span distance boundaries, drawing on our theoretical account of the ways in which virtual experiences can be accepted as real by interactive participants. If experiences in such places can become real for the participants, virtual travel could in the future replace our current disjointed social interactions over the Internet.

We have suggested that immersive VR and other technologies are likely to become increasingly popular as reasonably effective ways of experiencing a distant place and events presented there. VR can provide the most vivid sense of presence in another place, but can only realistically be used from a fixed, secure private and physical location. Meeting and visiting at a distance, via mobile devices and laptops, are increasingly popular, but the experience is less convincing and satisfying as digital travel. In what ways can we combine digital possibilities with social and physical realities to overcome some of these shortcomings?

In the rest of this section we consider how we could experience people and places through digital technology in the future, in light of discussions and findings from earlier chapters as well as the trends identified above.

\section{Metaphors and the Blending of Physical-Digital Realities}

Travel implies a journey, which involves a departure, a passage and an arrival. In touristic trips, and other types of temporary visit, there is travel from home to another, distant place, and then a return home again. Before travel, there is preparation and anticipation; after travel, recollection and sharing. When applied to digital travel, this is the "homeaway-back-home" metaphor (introduced in Chapter 1). The metaphor provides a starting point for designing more satisfactory ways of implementing digital travel. The most obvious of these is perhaps to mimic equivalent non-digital settings and interactions as closely as possible with appropriate technological capabilities and design, but this is both too ambitious and too limiting. It is too ambitious because far from everything about physical travel can be adequately simulated. It is too limiting because digital devices can transcend the restrictions of the physical (for example, with instant travel and instantaneous searches). 
However digital travel is realised, technically, it can be seen as a blend of the digital and the physical. With immersive VR, the blend is almost entirely digital, but some physical elements remain, since the traveller moves her body in physical space while experiencing the consequences within a virtual world. At the other extreme, the blend represented by standard video conference systems, used on phones or laptops, is heavily weighted towards the physical - the place where the traveller is actually located. Digital travel blends also occupy a position on what can be called the action dimension - the extent to which the traveller can act in the world they visit. With a social telepresence robot, for example, the traveller can move around in physical space, talk to people and sometimes make gestures, whereas a visit to a theatrical performance may be very vivid, but with no possibilities for action in the witnessed performance.

Waterworth and Hoshi (2016) suggest an approach to the design of interactive presence in what they call "everyday blended reality". Applying this approach to designing new ways of realising digital travel would represent an explicit attempt to blend the reality of physical travel with that of the interactive possibilities of digital media and devices. There is no single direction in which digital travel can be expected to evolve, but we can begin to re-imagine future digital travel possibilities as a set of different blends of the physical world and selected functionalities of digital devices. In the rest of this subsection we consider how the design process might work, and speculate on the possible outcomes.

As described by Imaz and Benyon (2006) "designing with blends" starts with a metaphor. A common example from HCI research is the computer desktop metaphor. The user interface appearance, and to some extent the behaviour from a user's perspective, is presented as a desktop, with folders, a trash can, objects that can be moved or opened by the user and so on. This is the familiar WIMP (Windows, Icons, Menus and a Pointer) interface common to most PCs. It is said to be a result of applying the desktop metaphor to the user interface of an operating system. As in any metaphor, it is somewhat like the thing it conveys (a physical desktop), but also very different. Imaz and Benyon (2006) point out that, although this started as being seen as metaphorical, it is no longer. Rather a "desktop" or "laptop" has become a thing in itself; as they put it, following Fauconnier and Turner (1998), a new "emergent space"-a concept in its own right.

Designing with blends works as shown in Fig. 6.1. There is a generic (conceptual) space that reflects the abstract structure and organisation of 


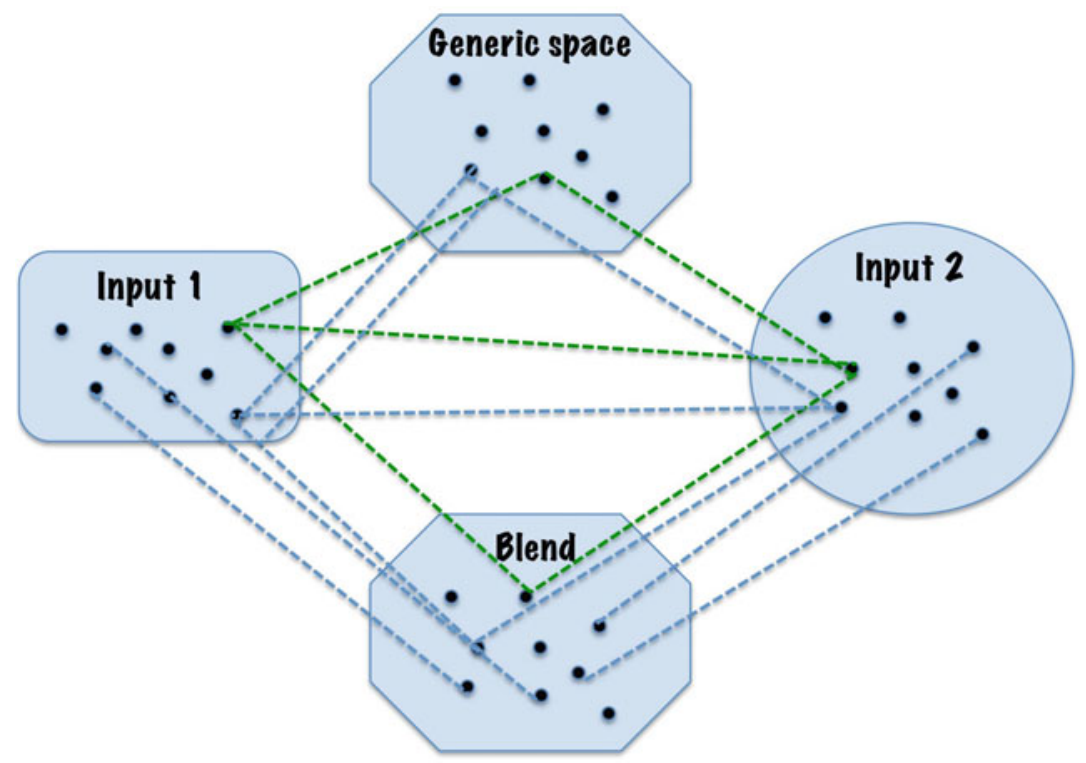

Fig. 6.1 Designing with blends

an overarching concept, such as in the above "desktop" example, office work. There are at least two "input" conceptual spaces, which in the same case might be "computer operations" and "physical office desktop". Each of these input spaces inherits some of the characteristics of the generic space, and also has other characteristics. A few of the characteristics are shared between the two input spaces; there is "cross-space mapping"; for example, "storage" and "trashing". Finally, some of the characteristics of the input spaces are merged into the blend, a new emergent structure; in this case this would be a high-level design space for an interface partially based on the metaphorical idea that a computer is a desktop; the familiar desktop we all use, and which is now not metaphorical, but a thing in itself. It is also possible to use two or more emergent blend spaces as inputs to further blending.

Waterworth and Hoshi (2016) used this approach to design "blended everyday realities" in which elderly users could interact, with technologies embedded in their environment, via ambient input objects and display devices, using simple movements and peripheral perception. In the same 
way, we can imagine the use of blending to create one or more toplevel designs for future digital travel systems, combining some features of physical travel with selected functionalities of digital communications technologies. Blended conceptual space is an emergent conceptual structure that can incorporate new ideas and insights. It can include new emergent properties that exist neither in the world of physical travel nor the domain of existing interactive functionalities.

Table 6.1 shows how blending might work when designing some form of digital travel (one of many possible ways of blending on this topic) based on the metaphor "To use my device is to be a traveller". In this case, input space-1 refers to the frame of ways of utilising current interactive technologies (functionalities of devices), input space-2 refers to the frame of conventional ways of travelling and input space- 3 refers to aspects of embodiment. The generic space that maps onto each of the inputs contains some of the characteristics they have in common, and reflects more abstract structure and organisation shared by the inputs, that of navigating in physical space (making journeys, traversing distance and social interaction to find the way). The resultant blended space-HCI is travel (To use my device is to be a traveller) - is the start of a potentially new way of thinking about digital travel. There are many possible ways of deriving a blended space, depending on the metaphor chosen and

Table 6.1 Blending applied to the metaphor "To use my device is to be a traveller"

\begin{tabular}{lllll}
\hline $\begin{array}{l}\text { Generic space: } \\
\text { Navigation }\end{array}$ & $\begin{array}{l}\text { Input space 1: } \\
\text { Tech features }\end{array}$ & $\begin{array}{l}\text { Input space 2: } \\
\text { Travel }\end{array}$ & $\begin{array}{l}\text { Input space 3: } \\
\text { Embodiment }\end{array}$ & $\begin{array}{l}\text { Blended space: } \\
\text { HCI is travel }\end{array}$ \\
\hline Space & Sensors & Getting lost & Moving & 3D Space \\
Topography & Messages & Distance & Gazing & Places \\
Landmarks & Input-output & Landmarks & Touching & Landmarks \\
Distance & Icons & Meetings & Hiding & Selection \\
Signposts & Selection & Time & Pointing & Moving \\
Meetings & Sound & Preparation & Turning & Leaving-arriving \\
Time & 3D space & Leaving-arriving & Resting & Meeting \\
Danger & Animation & Sightseeing & Listening & Sightseeing \\
Movement & Gestures & Taking photos & Falling & Saving images \\
Leaving-arriving & Meetings & Remembering & Balancing & Sounds \\
Getting lost & Movement & Places & Placing & Input-output \\
Memory & Memory & Memory & Memory & Memory \\
\hline
\end{tabular}


the features selected from the two input spaces; there are thus very many possible new designs. It is also possible to blend the blends, by using the features of two (or more) blended spaces as the input spaces for further blending.

Several other metaphors seem promising as a basis for designing future blends. The following is an initial list of candidates:

- When I turn on my computer I become a traveller

- A videoconference is a short visit to another place

- Browsing the Internet is a journey

- My phone is my home

- My PC is a vehicle

- Interaction is an adventure

- I leave home when I use my device, then later I return

- When I visit digital places, I am inside and outside at the same time.

In the next section, we complete our journey through the book, concluding our argument that the feeling one is actually in a placethe feeling of "being there"-is vital to the quality and success of virtual social interactions and travels to distant (or fictional) places. This is especially relevant at times when travel is restricted or prohibited, since a lack of travel can mean few social opportunities, leading to a sense of isolation and sometimes depression. Currently, however, virtual travel is unlike physical travel in many significant respects, and does not adequately satisfy the socio-psychological needs of people meeting, of tourists and of other travellers. As we suggested above, new ways of thinking about digital travel are called for.

\section{Reflecting on Our Journey so Far, and Our Plans}

Digital travel is about the sense of being there; being there without having to go there. We motivated our journey into this territory by noting that people increasingly travel, visit and meet other people in computermediated environments, and that this trend has been boosted by the covid-19 pandemic from 2020 onwards. Before that, videoconferencing and other technologies were already in widespread use by businesses and as a way for families and friends to keep in touch over distances. Recent developments have led to many other kinds of meetings and events taking place without physical travel. This trend seems likely to continue, with 
more and more people meeting and visiting places via digital environments and interactions. But, as we have suggested, current technologies for realising these kinds of digital travel do not succeed in matching the psychosocial needs of participants (Bailenson, 2021). In trying to understand and move on from this situation, we planned an itinerary for our journey via a series of waypoints; each of these allowing one facet of digital travel-being there in a distant place - to be examined in detail. We reflect on our journey through the book in the rest of this section.

Our first waypoint on our journey through the book was characterised by a focus on the being in being there. How can we be anywhere? It turns out that we cannot be without being somewhere, and that this is naturally the place in which our bodies are located. We presented different philosophical and psychological perspectives on having the experience of being somewhere, stressing the role of perception. The motivation for this was to shed light on ways of understanding the experience of being in another world created or mediated by digital technology. We looked at representationalism, relationism, enactivism and the sense-data view, and concluded that relationism offers the best understanding of perceptual illusions from an ordinary person's perspective, a popular way of defining telepresence experiences. We also suggested that enactivism is also very relevant to understanding presence, because it stresses that experiences are inseparable from the perceiver's bodily activities. Enactivism was heavily influenced by the work of Merleau-Ponty (1962). Both of these approaches have something to add to our understanding of the phenomena of digital travel. Representationalism is probably not well known to many readers, but it has a straightforward answer to many of the hard questions by claiming that what we see or experience are representations in the brain.

Moving on to more practical psychological perspectives, we introduced dual process theories of cognition (Kahneman, 2002; Stanovich \& West, 2000), and suggested that acceptance of the reality of an external world, in the moment, is largely a result of intuitive, rapid cognitive processing. One for the first to observe this was the philosopher Baruch Spinoza.

Merleau-Ponty's views on perception (Merleau-Ponty, 1962), based in the relationship between the world, embodiment, action and perception, also led us into a focus on transparency in interactions with the worldtechnology that disappears from attention — and so with digitally mediated environments. Direct perception accounts of presence are appealing in the 
way embodiment is seen as linking mind and body, with perception understood as happening "out there", not in the brain, both in our perceptions of the physical world and of compellingly rendered virtual worlds. This a key idea for understanding how digital travel can be experienced as perceptually real. Enactivism and the direct perception approach both stress that the possibilities for action in the world are important for the experience of it. This, in turn, is influenced by the characteristics of the world in which we act, through what are known as affordances.

This brings us to our second waypoint, a consideration of the question: what is telepresence? How can technology provide us with the means to escape our bodies, in some sense, and be there-where "there" is another place, a place other than where our bodies are physically located? To address this question we compared and contrasted different theoretical accounts of telepresence, including presence as a pretence (a simulation of reality [Slater, 2009]), as pretending (making believe the virtual world is real [Turner 2016, Turner et al., 2016]), as a perceptual illusion ("the illusion of non-mediation" [Lombard \& Ditton, 1997; Riva, 1999]), and as embodied attention to the surrounding (or apparently surrounding) environment. Waterworth et al. $(2015,2020)$ define presence as "the feeling of being located in a perceptible external world around the self", and suggest that "Varying feelings of presence reflect the extent to which attention is focused on the external environment". These views are all well-accepted in the field, and all can be seen as contributing to a virtual travel experience.

When we feel highly present, we believe in the perceived world in which we experience ourselves to be. In that moment it is real to us. Creating that effect is a key part of a convincing digital travel experience. To have that experience, we must be attending to the digital world, feeling as if we are (as-if-physically) surrounded by it. When that is achieved, our imaginations are involved in at least two ways: in how we perceive our surroundings, and in how we conceptualise our being there. While we do not think that we need to make-believe (that the world is real), we do use our imagination, and memory, to make sense of what happens there. The world may be a simulation, be veridical, be misperceived or even be an hallucination. In the moment of a vivid digital travel experience we do not reflect on this question, we just have the experience. But we do believe that it is veridical. When we later recall and talk about our experience, it is as if it were real. At the same time, we refer to it as a digital experience because we can reflect and reason that to have been the case. 
Our next area of focus was characterised by an examination of notions of place, as outlined in work in tourism studies and other applied social fields, focusing on the factors affecting sense of place (Relph, 1976) and on how and when different experiences of place arise in the traveller. The aim was to understand the factors that can be expected to contribute to the digital experience of a distant place. Marketing and hedonic consumption were also seen to be useful in understanding travel and travellers (e.g. Hirschman \& Holbrook, 1982; Holbrook \& Hirschman, 1982), for example, through the mechanisms of expressed intentions to visit a place and word of mouth recommendations.

The tourist experience is an amalgam of different experiences (see, e.g., Cohen, 1979). It involves all senses and therefore their impact should not be overlooked in efforts to theorise tourism's experiential dimensions. A key question concerns the ways in which digital experiences are similar to or different from in situ experiences. We found that virtual travel is unlike physical travel in many significant respects, but the experience of a place-assuming the telepresence feeling of being there has been achieved, is psychosocially similar. For digital travel and digital experiences too, place attachment is a relevant concept for places that a person knows well. Put another way, a digital experience can become a spatial experience if our bodily senses are invoked by the virtual place. A key element in a memorable experience is perceived realness. We concluded that facts and accuracy have a similar role in digital experiences as in in situ experiences.

Our next stop was to consider empirical findings about the extent to which some current technologies can elicit a sense of presence, and place. We investigated and reported on factors affecting the sense of place experience, and telepresence, using a video game environment to facilitate sightseeing behaviour among participants in the study. We went on to explore in detail people's attitudes to physical travel and digital travel, both in the present and in the future. Interestingly, we were able to identify a subset of people whom we can already categorise as "digital travellers". What will they encounter on their future digital travels?

Finally, in the present chapter, we considered selected trends in technologies used to enable various forms of digital travel, before outlining an approach to thinking about new possibilities for implementing digital travel based on metaphors and blending theory.

Despite our view that digital travel opens up many new possibilities, we recognise that these may not be entirely benign. Nor do they always go one way, with the physical influencing the virtual experience. Some 
people are overwhelmed by awe when they visit a place they have read about in a novel, or seen in paintings. This may also happen with places that have been experienced in virtual reality, say when planning a trip. The actual place may overwhelm the visitor. On the other hand, the opposite effect is perhaps more usual; the carefully selected and presented glimpses of places experienced in digital promotional media may lead to the visitor being disappointed and less able to enjoy the real possibilities of the actual place. There may also be a kind of inverse presence (Timmins \& Lombard, 2005 ), in which the actual place does not seem as real as a digital version. It may become the case for some that actual places do not seem real unless they can also be visited digitally. Physical places without Internet access (there are still many of these) may seem less real than other places, because visitors cannot share their experience of the place with distant others.

The more we are sharing our experiences of the moment with distant others, the less we may seem to be really there, where we physically are. This is one of the comforting aspects of ubiquitous use of a mobile phone: we can always escape, mentally, from where we physically are. We may never really be there, in terms of our immediate experiences. And yet, one of the joys of travel is to explore the unknown. If we reply too heavily on digital previews, real-time dynamic maps with predefined routes and labels, and so on, we lose the opportunity to stumble on something rewarding, by chance. But we also remove the possibility of getting lost, and often reduce the level of danger we may expose ourselves to in risky neighbourhoods. From this we can see that digital travel lacks, and probably always will lack, the open elements of the unexpected that some would say is essential to real travel (e.g. Leed, 1991).

For the future, we plan to explore more ways of blending features from the universe of travel and that of technical devices and their interaction possibilities. For example, the metaphor "My phone is my home" is intriguing, due to the apparent contradiction of a device that permits contact with other people and places around the world becoming the safe haven to be returned to during travels in the physical world. An alternative metaphor would be "My phone is an extra set of eyes and ears that allow me to see and hear distant people and places". More generally, we believe that the impact of the level of presence experienced during digital travel will become more recognised and significant, including as a factor to deliberately consider during the design process. Selectable, or automatically variable, presence would seem to be a necessary feature, to balance 
the need for vivid experiences of other places with the needs of attending to significant events in the physical world.

Digital technology is used more and more in our society today, for everyday tasks, in gaming and entertainment and especially for communication at a distance. Technological development continues rapidly, but there is a need for more insight into the factors that support successful and satisfying interaction at a distance. In games and in movies we can see examples of what we might see in the future as consumer technology and in professional use. Movies and games have a story, a narrative, and we suggest that it is also partly due to there being a good story that we can have a real travel experience. It was noteworthy that some participants experiencing virtual sightseeing in our Los Angeles study felt the experience to be similar to visiting the actual place.

Many questions remain, but we believe that the physical and the virtual can be blended to support embodied interaction in integrated digital places. If digital places can become the object of real visits for participants, not only in the moment, but as lasting, memorable experiences of being there, subjectively real virtual travel could replace the disjointed social interactions through the Internet with which we have all become so familiar. In them, it should be possible to maintain role-sensitive social aspects of communication and behaviour.

Technology can be seen as taking us out into the world, to distant places. But it also brings the world to us, to our devices. Will we leave home to navigate, discover and experience distant digital worlds; worlds that we experience as reality? Or will the distinction between home and digital worlds disappear, as we carry with us the means to access distant people and places at any time, and from everywhere we go?

\section{REFERENCES}

Ahn, S. J., \& Bailenson, J. N. (2011). Self-endorsing versus other-endorsing in virtual environments. Journal of Advertising, 40(2), 93-106. https://doi. org/10.2753/JOA0091-3367400207

Bailenson, J. N. (2021). Nonverbal overload: A theoretical argument for the causes of Zoom fatigue. Technology, Mind, and Behavior, 2(1). https://doi. org/10.1037/tmb0000030

Cohen, E. (1979). Rethinking the sociology of tourism. Annals of Tourism Research, 6(1), 18-35. https://doi.org/10.1016/0160-7383(79)90092-6 
Cui, G., Lockee, B., \& Meng, C. (2013). Building modern online social presence: A review of social presence theory and its instructional design implications for future trends. Education and Information Technologies, 18(4), 661-685. https://doi.org/10.1007/s10639-012-9192-1

Fauconnier, G., \& Turner, M. (1998). Conceptual integration networks. Cognitive Science, 22(2), 133-187. https://doi.org/10.1207/s15516709cog 2202_1

Fauville, G., Luo, M., Queiroz, A. C. M., Bailenson, J. N., \& Hancock, J. (2021). Nonverbal mechanisms predict zoom fatigue and explain why women experience higher levels than men. SSRN Electronic Journal. https://doi.org/ $10.2139 /$ ssrn. 3820035

Gunawardena, C. N. (1995). Social presence theory and implications for interaction collaborative learning in computer conferences. International Journal of Educational Telecommunications, 1(2-3), 147-166.

Hirschman, E. C., \& Holbrook, M. B. (1982). Hedonic consumption: Emerging concepts, methods and propositions. Journal of Marketing, 46(3), 92. https://doi.org/10.2307/1251707

Holbrook, M. B., \& Hirschman, E. C. (1982). The Experiential aspects of consumption: Consumer fantasies, feelings, and fun. Journal of Consumer Research, 9(2), 132. https://doi.org/10.1086/208906

Imaz, M., \& Benyon, D. (2006). Designing with blends: Conceptual foundations of human-computer interaction and software engineering. MIT Press. https:// doi.org/10.7551/mitpress/2377.001.0001

Isabet, B., Pino, M., Lewis, M., Benveniste, S., \& Rigaud, A.-S. (2021). Social telepresence robots: A narrative review of experiments involving older adults before and during the COVID-19 pandemic. International Journal of Environmental Research and Public Health, 18(7), 3597. https://doi.org/10. $3390 /$ ijerph18073597

Kahneman, D. (2002). Daniel Kahneman-Prize Lecture. https://www.nobelp rize.org/prizes/economic-sciences/2002/kahneman/lecture/

Kristoffersson, A., Coradeschi, S., \& Loutfi, A. (2013). A review of mobile robotic telepresence. Advances in Human-Computer Interaction, 2013, 1-17. https://doi.org/10.1155/2013/902316

Leed, E. J. (1991). The mind of the traveler: From Gilgamesh to global tourism. Basic books.

Lombard, M., \& Ditton, T. (1997). At the heart of it all: The concept of presence. Journal of Computer-Mediated Communication, 3(2). https://doi.org/ 10.1111/j.1083-6101.1997.tb00072.x

Merleau-Ponty, M. (1962). Phenomenology of perception (1962 [Paris: Gallimard, 1945]). Routledge and Kegan Paul. 
Meyrowitz, J. (1986). No sense of place: The impact of electronic media on social behavior (1. issued as an Oxford University Press paperback). Oxford University Press.

Relph, E. (1976). Place and placelessness. SAGE.

Riva, G. (1999). From technology to communication: Psycho-social issues in developing virtual environments. Journal of Visual Languages \& Computing, 10(1), 87-97. https://doi.org/10.1006/jvlc.1998.0110

Shakeri, H., \& Neustaedter, C. (2019). Teledrone: Shared outdoor exploration using telepresence drones. In Conference companion publication of the 2019 on computer supported cooperative work and social computing, pp. 367-371. https://doi.org/10.1145/3311957.3359475

Short, J., Williams, E., \& Bruce, C. (1976). The social psychology of telecommunications. Wiley.

Slater, M. (2009). Place illusion and plausibility can lead to realistic behaviour in immersive virtual environments. Philosophical Transactions of the Royal Society b: Biological Sciences, 364(1535), 3549-3557. https://doi.org/10.1098/rstb. 2009.0138

Stanovich, K. E., \& West, R. F. (2000). Individual differences in reasoning: Implications for the rationality debate? Behavioral and Brain Sciences, 23(5), 645-665. https://doi.org/10.1017/S0140525X00003435

Timmins, L. R., \& Lombard, M. (2005). When "Real" seems mediated: Inverse presence. Presence: Teleoperators and Virtual Environments, 14(4), 492-500.

Tsui, K. M., Desai, M., Yanco, H. A., \& Uhlik, C. (2011). Exploring use cases for telepresence robots. In Proceedings of the 6th international conference on human-robot interaction-HRI '11, 11. https://doi.org/10.1145/1957656. 1957664

Turner, P. (2016). Making-believe with technology. In P. Turner (Ed.), HCI Redux (pp. 131-149). Springer International Publishing. https://doi.org/ 10.1007/978-3-319-42235-0_8

Turner, S., Huang, C.-W., Burrows, L., \& Turner, P. (2016). Make-believing virtual realities. In P. Turner \& J. T. Harviainen (Eds.), Digital make-believe (pp. 27-47). Springer International Publishing. https://doi.org/10.1007/ 978-3-319-29553-4_3

Waterworth, J. A. (1985). Why is synthetic speech harder to remember than natural speech? In Proceedings of the SIGCHI conference on human factors in computing systems-CHI '85, 201-206. https://doi.org/10.1145/317456. 317493

Waterworth, J. A., Chignell, M., \& Moller, H. (2020). Age-sensitive well-being support. In Technology and health (pp. 67-88). Elsevier. https://doi.org/10. 1016/B978-0-12-816958-2.00004-6

Waterworth, J. A., Waterworth, E. L., Riva, G., \& Mantovani, F. (2015). Presence: Form, content and consciousness. In M. Lombard, F. Biocca, 
J. Freeman, W. IJsselsteijn, \& R. J. Schaevitz (Eds.), Immersed in media (pp. 35-58). Springer International Publishing. https://doi.org/10.1007/ 978-3-319-10190-3_3

Waterworth, J., \& Hoshi, K. (2016). Human-experiential design of presence in everyday blended reality. Springer International Publishing. https://doi.org/ 10.1007/978-3-319-30334-5

Wired. (2021). Google's Project Starline videoconference tech wants to turn you into a Hologram. Lauren Goode (journalist), May 18, 2021. https://www. wired.com/story/google-project-starline/

Open Access This chapter is licensed under the terms of the Creative Commons Attribution 4.0 International License (http://creativecommons.org/licenses/ by $/ 4.0 /)$, which permits use, sharing, adaptation, distribution and reproduction in any medium or format, as long as you give appropriate credit to the original author(s) and the source, provide a link to the Creative Commons license and indicate if changes were made.

The images or other third party material in this chapter are included in the chapter's Creative Commons license, unless indicated otherwise in a credit line to the material. If material is not included in the chapter's Creative Commons license and your intended use is not permitted by statutory regulation or exceeds the permitted use, you will need to obtain permission directly from the copyright holder.

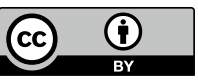

